\title{
A FORMAÇÃO PROFISSIONAL EM LAZER NA CIDADE DE BELÉM E O OLHAR DISCENTE
}

Recebido em: 30/12/2015

Aceito em: 27/09/2015

\author{
Gustavo Maneschy Montenegrol \\ Universidade Federal do Amapá (UNIFAP) \\ Macapá - AP - Brasil \\ Universidade Federal de Minas Gerais (UFMG) \\ Belo Horizonte - MG - Brasil
}

RESUMO: Este artigo objetiva analisar o entendimento de lazer sustentado pelos acadêmicos que cursaram, em 2011, o último semestre de Educação Física nas Universidades Públicas da Cidade de Belém e identificar se as disciplinas sobre lazer, frequentadas na graduação, atenderam as expectativas profissionais dos alunos. Participaram da pesquisa 12 discentes, sendo 7 estudantes da Universidade do Estado do Pará - UEPA e 5 da Universidade Federal do Pará - UFPA. As falas produzidas pelos acadêmicos foram capturadas a partir de entrevista semiestruturada com posterior análise por meio da Técnica de Elaboração e Análise de Unidades de Significado. Com esta pesquisa, constatou-se que 58,33\% dos alunos apresentaram um entendimento funcionalista do lazer e $25 \%$ indicou a necessidade de ampliação de discussões sobre o lazer no currículo das instituições investigadas.

PALAVRAS CHAVE: Atividades de Lazer. Educação Física e Treinamento. Desenvolvimento de Pessoal.

\section{VOCATIONAL TRAINING IN LEISURE IN BELÉM CITY AND UNDERSTANDING OF STUDENTS}

ABSTRACT: This article aims to analyze the pleasure of understanding sustained by academics who attended, in 2011, the last semester of physical education in public universities of Belem city and identify whether the disciplines of leisure, to attend the graduation, attended the professional expectations of studentes. The participants were 12 students , 7 students from Pará State University - UEPA and 5 of the Federal University of Pará - UFPA. The reports produced by the students were captured through semi-structured interviews with subsequent analysis by Technical Development and Analysis of Meaning Units. With this research, it was found that 58,33\% of the students showed functionalist understanding of leisure and $25 \%$ indicated the need to expand discussions about leisure in the curriculum of institutions investigated.

\footnotetext{
${ }^{1}$ Professor da Universidade Federal do Amapá. Doutorando em Estudos do Lazer pela Universidade Federal de Minas Gerais.
} 
KEYWORDS: Leisure Activities. Physical Education and Training. Staff Development.

\section{Introdução}

Quando observamos a história da formação/atuação profissional em Educação Física, identifica-se que existem, desde as primeiras preocupações com o lazer no Brasil $^{2}$, algumas conexões com a Educação Física, em virtude do privilégio dado às práticas esportivas ou programas de atividades físicas nos projetos da área.

Melo (2003) ensina que esse fato contribuiu para a importância que as atividades físicas e recreativas ganharam no Brasil, compreendidas como possibilidade de recuperar a força de trabalho; como componente na manutenção da saúde (CAMPOS e ALENCAR, 2013). Nesse contexto, o profissional de Educação Física estava habilitado para atuar nas ações e projetos de lazer.

Autores como Melo (2003), Pinto (2008), Marcellino (2010), Campos e Alencar (2013) indicam que desde as décadas iniciais do Século XX algumas ações governamentais passaram a fomentar políticas de criação de espaços de recreação/lazer, balizadas por meio de um modelo associado nas atividades físicas e recreativas. De acordo com os autores, estas vivências eram materializadas por meio de jogos, de ginástica, corridas, torneios, atividades rítmicas, danças e, em um plano menor, as atividades artísticas.

Como salienta Melo (2003), a formação profissional na Educação Física já mostrava preocupações com a capacitação de alunos para atuar na área da “recreação/lazer" desde os anos de 1930, onde surgiram importantes ações, como a

\footnotetext{
${ }^{2}$ Melo (2003) e Gomes (2003) situam que as primeiras preocupações, podemos assim chamar, mais sistematizadas sobre o lazer no Brasil, se corporificaram por meio da implementação de políticas de recreação nos anos 30 e 40 do Século XX. Um exemplo disso, afirma Gomes (2003), foi a criação, em 1943, do Serviço de Recreação Operária, pelo Ministério do Trabalho, Indústria e Comércio, na Era Vargas.
} 
criação de cursos no Espírito Santo (1932), em São Paulo (1934) e no Rio Grande do Sul (1940); a criação da Escola de Educação Física do Exército (1933) e a fundação da Escola Nacional de Educação Física e Desportos (ENEFD), na Universidade do Brasil (1939).

$\mathrm{Na}$ trilha deste raciocínio, é possível situar o pensamento de Marcellino (2010), quando afirma que tradicionalmente, a Educação Física presta serviços na área de Recreação e Lazer desde as décadas iniciais do século XX, embora somente na década de 1960 a Recreação tenha sido incluída formalmente na formação do profissional. Para o autor, "a grande vinculação entre educação física e recreação/lazer é vista no Brasil, no caminho histórico da ação profissional desde os anos de 1930" (MARCELLINO, 2010, p. 61).

Em um contexto atual, evidencia-se que o lazer se apresenta como um significativo campo de atuação profissional seja em clubes, escolas, na promoção da saúde, políticas públicas de esporte e lazer, colônia de férias, na gestão de eventos sobre o lazer e na pesquisa (ISAYAMA, 2009), o que se faz necessário, portanto, conhecer a compreensão de lazer sustentada por profissionais e acadêmicos que atuam/atuarão nestes espaços.

Quando se recorre aos estudos de Isayama (2002, 2003, 2010) logo identifica-se que o lazer tem se destacado como um fenômeno social contemporâneo, evidenciandose como objeto de pesquisa, de estudo e de formação/atuação profissional de diferentes disciplinas e de múltiplos campos do conhecimento, configurando, assim, o seu caráter multidisciplinar (ISAYAMA, 2010).

Destaca-se que o lazer vem sendo pensado como ponto de partida para analisar a própria sociedade e seus valores, já que não pode ser desvinculado de outros planos da 
vida social (GOMES, 2010). Em decorrência disso, a formação de profissionais para atuar neste campo de estudos e intervenções surge como preocupação central de estudantes, profissionais e pesquisadores.

É preciso ressaltar que muitos dos espaços de formação procuram trilhar uma perspectiva que se limita a uma abordagem técnica e instrumental, em que o lazer ainda é visto como um "pacote de atividades" seja por meio de brincadeiras, de jogos, de "técnicas" recreativas e até mesmo nas atividades físico-esportivas do lazer (ISAYAMA, 2002, 2010).

Sendo assim, advoga-se que a formação em lazer deve ser compreendida como um eixo privilegiado de ação para se alçar o desenvolvimento de políticas públicas e intervenção pedagógica compromissada com a melhoria de vida da população.

No que tange a questão da formação profissional em lazer na Região Norte, com destaque para o estado do Pará, é possível notar a ampliação de possibilidades de formação nos cursos de Educação Física da cidade de Belém. Ao observar essa questão, Campos e Alencar (2013) destacam que três, dos quatro cursos existentes na cidade, destinam pelo menos uma disciplina voltada ao ensino do lazer.

Montenegro $(2012,2014)^{3}$ reforça que esta formação é pensada de maneira crítica, embora as instituições desenvolvam propostas formativas diferenciadas. Assim, ele afirma:

Na UEPA, a discussão do lazer tem o seu núcleo voltado para reflexões de temas como: políticas públicas, formação humana e intervenção profissional, enfoque sociohistorico do lazer, lazer e sociedade [...] No que se refere ao Curso de Educação Física da UFPA, foi possível perceber conhecimentos sobre o lazer que seguem orientação didático-metodológico, destacando-se temas como: Programação e execução de atividades voltada para o lazer;

\footnotetext{
${ }^{3} \mathrm{O}$ autor analisou a proposta de formação voltada ao lazer desenvolvida nos cursos de Educação Física das universidades públicas da cidade de Belém, sendo elas a Universidade do Estado do Pará e a Universidade Federal do Pará.
} 
construção e aplicação de intervenção pedagógica (MONTENEGRO, 2014, p. 133).

Esta constatação levou ao seguinte questionamento: em que medida os alunos formandos destas instituições têm se apropriado dos conhecimentos sobre o lazer desenvolvidos durante o seu processo de formação? Neste sentido, os objetivos que orientaram a pesquisa foram: analisar o entendimento de lazer sustentado pelos acadêmicos que cursaram, em 2011, o último semestre de Educação Física, nas Universidades Públicas da cidade de Belém e identificar se as disciplinas sobre lazer, frequentadas na graduação, atenderam as expectativas profissionais dos alunos.

Participaram da pesquisa 12 alunos, sendo 7 estudantes da Universidade do Estado do Pará - UEPA e 5 da Universidade Federal do Pará - UFPA.

Ressalta-se que esta pesquisa é parte integrante dos resultados apresentados na Dissertação de Mestrado " ${ }^{4}$ Conhecimento sobre o lazer na formação de professores de Educação Física: um olhar sobre os cursos superiores das Universidades Públicas em Belém/PA", a qual foi apresentada junto ao Programa de Pós-Graduação em Educação da Universidade Federal do Pará.

\section{Metodologia}

Esse estudo assume os pressupostos da Pesquisa Qualitativa que, segundo André e Lüdke (1986), trata-se de um modelo de investigação no qual envolve a obtenção de dados a partir do contato direto do pesquisador com a situação estudada, enfatizando

\footnotetext{
${ }^{4}$ MONTENEGRO, Gusatavo Maneschy. Conhecimento sobre o lazer na formação de professores de Educação Física: um olhar sobre os cursos superiores das universidades públicas em Belém/PA. 2012. 190f. Dissertação (Mestrado em Educação)-Instituto de Ciências da Educação, Universidade Federal do Pará, Belém, 2012.
} 
mais o processo do que o produto e se preocupando em explicitar as perspectivas dos participantes.

De acordo com as autoras, na pesquisa qualitativa, “[...] os pesquisadores não se preocupam em buscar evidências que comprovem hipóteses definidas antes do início do estudo. As abstrações se formam ou se consolidam basicamente [...] à medida que o estudo se desenvolve" (ANDRÉ; LÜDKE, 1986, p. 13).

Como a intenção era estar o mais próximo do objeto de investigação, optou-se pela pesquisa qualitativa, pois ela permite "uma imersão do pesquisador na vida e no contexto" (CHIZZOTTI, 2005, p. 81) do objeto pesquisado e, vale-se da interpretação do fenômeno, levando em consideração toda sua subjetividade, com o intuito de decodificar e de revelar sua complexidade (ANDRÉ; LÜDKE, 1986).

Para a realização deste estudo, aceitaram participar 12 alunos, sendo sete discentes da UEPA e cinco da UFPA. É importante destacar que a partir da perspectiva da pesquisa qualitativa, não existe a necessidade de definir, a priori, o número de sujeitos a serem entrevistados, pois o quantitativo de participantes depende da qualidade de informações (ANDRÉ; LÜDKE, 1986), da profundidade, do grau de recorrência e de divergência obtidas em cada depoimento (DUARTE, 2002).

Foi estabelecido que o critério para a participação dos discentes seria: estar cursando o oitavo semestre dos cursos de Educação Física da UEPA e da UFPA; disponibilização, livremente, para a participação na pesquisa e que preenchessem e assinassem o Termo de Consentimento Livre e Esclarecido - TCLE. Faz-se necessário ressaltar que ficou estabelecido em conversa prévia com os alunos, que a identidade deles não seria revelada. 
As entrevistas só foram realizadas a partir da sua aprovação pelo Comitê de Ética de Pesquisas com Seres Humanos do Instituto de Ciências da Saúde da Universidade Federal do Pará (CEP-ICS/UFPA) ${ }^{5}$, aprovado com o CAAE 0030. 0. 073. 000-11 e parecer $n^{\circ} 035 / 11$.

Para a coleta de dados, utilizou-se a técnica da entrevista semiestruturada, a qual se "[...] desenrola a partir de um esquema básico, porém, não aplicado rigidamente, permitindo que o entrevistador faça as necessárias adaptações" (ANDRÉ; LÜDKE, 1986, p. 34).

As autoras defendem que esse tipo de entrevista aproxima-se de um esquema mais acessível, menos estruturado, podendo contribuir para que o informante sinta-se mais livre em discorrer sobre o tema. De acordo com as pesquisadoras, esta técnica possui grande vantagem sobre outros procedimentos metodológicos, pois “[...] permite a captação imediata e corrente da informação desejada, praticamente com qualquer tipo de informante e sobre vários tópicos. Uma entrevista bem-feita pode permitir o tratamento de assuntos de natureza estritamente pessoal" (ANDRÉ; LÜDKE, 1986, p. $34)$.

Chizzotti (2005, p. 93) afirma que a entrevista é uma forma de colher informações baseada no discurso livre do entrevistado, a qual possibilita que este possa "[...] exprimir-se com clareza sobre questões da sua experiência e comunicar representações e análises suas, prestar informações fidedignas, manifestar em seus atos o significado que têm no contexto em que eles realizam”.

As falas produzidas pelos discentes foram analisadas com base na Técnica de Elaboração e Análise de Unidades de Significado (MOREIRA; SIMÕES; PORTO;

\footnotetext{
${ }^{5}$ Complexo de Sala de Aula/ICS - Sala 13 - Campus Universitário, n. ${ }^{\circ}$ 01, Guamá - CEP:66075-110, CAAE 0030.0.073.000-11 e parecer número 35/11
} 
2005, p. 108), a qual procura “[...] desvelar os significados de discursos, proferidos por corpos que apresentam experiências significantes, como veículos de comunicação com o mundo".

Essa técnica se estrutura nas etapas descritas pelos autores:

$1^{\circ}$ etapa: Relato Ingênuo - Apreensão e entendimento dos discursos dos sujeitos com base na aplicação de questões geradoras, as quais devem provocar os entrevistados a emitir seus pensamentos com detalhes;

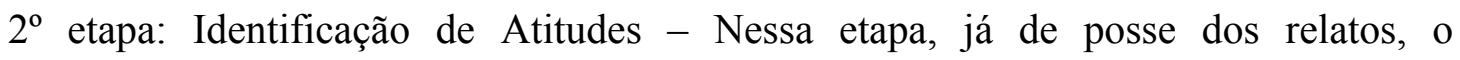
pesquisador deve voltar-se várias vezes aos discursos das pessoas entrevistadas, para buscar captar o sentido do todo das suas falas, além de selecionar as unidades mais significativas dos discursos dos sujeitos, procurando indicadores e categorias que possam servir de análise para a interpretação.

$3^{\circ}$ etapa: Interpretação - Com o quadro geral das ideias de cada sujeito montado e caracterizado pela identificação das unidades de significado, bem como as convergências e divergências, o pesquisador passa a fazer a análise interpretativa do fenômeno, buscando compreendê-lo em sua essência, esta entendida como possibilidade de se manifestar após o desvelamento das ideologias que permeiam os discursos dos sujeitos.

Foi informado aos alunos que a entrevista continha duas perguntas, que seriam feitas uma de cada vez, ou seja, que a segunda pergunta só seria aplicada depois que a primeira tivesse sido completamente respondida; que deveriam usar o tempo que achassem necessário para responder, e que suas respostas fossem pensadas no sentido de falarem tudo o que soubessem e/ou quisessem a respeito da pergunta. 
A primeira pergunta aplicada teve a intenção de identificar a compreensão de lazer sustentada pelos alunos. Sendo assim, ela ficou da seguinte forma redigida: O que é lazer para você?

Na segunda pergunta, a intenção foi compreender, a partir do olhar discente, se a disciplina ligada a temática do lazer, cursada na graduação ${ }^{6}$, atendeu as suas expectativas profissionais. Portanto, a questão dois ficou escrita assim: A disciplina sobre lazer que você cursou durante a sua formação atendeu as suas expectativas profissionais? Justifique.

O contato com os alunos, para a realização das entrevistas, não foi fácil, pois a maioria dos discentes se negou a participar, alegando, por exemplo, que naquele momento não poderiam, que estavam no tempo de aula. Além do mais, vários discentes declararam falta de segurança para responder as questões.

Ciente da dificuldade entrou-se em contato com vários professores das instituições e com os Centros Acadêmicos dos cursos, para que estes pudessem indicar ou facilitar a aproximação com os alunos. Foi por intermédios destes que se conseguiu o quantitativo exposto para a realização da pesquisa.

\section{Resultados e Discussões}

A primeira pergunta geradora a ser aplicada e ter as suas Unidades de Significados reveladas foi: O que é lazer para você? Mediante as respostas, foram identificadas dezenove unidades de significados. Porém, após várias leituras das falas, agruparam-se as que se equiparavam e, após isso, foram capturadas quatro unidades mais significativas, as quais são apresentados no (QUADRO 1).

\footnotetext{
${ }^{6}$ Ambas as instituições investigadas apresentam apenas uma disciplina voltada à discussão do lazer. Na UEPA, a disciplina denomina-se "Estudos do Lazer" e na UFPA "Recreação e Lazer na Sociedade".
} 
Quadro 1: Unidades de significados da primeira pergunta

\begin{tabular}{|c|c|c|c|c|c|c|c|c|c|c|c|c|c|c|}
\hline $\begin{array}{l}\text { Unidades de } \\
\text { Significados }\end{array}$ & 1 & 2 & 3 & 4 & 5 & 6 & 7 & 8 & 9 & 10 & 11 & 12 & $\%$ & Total \\
\hline Visão Funcionalista & $\mathrm{X}$ & $\mathrm{X}$ & $\mathrm{X}$ & $\mathrm{X}$ & & & $\mathrm{X}$ & $\mathrm{X}$ & & & & $\mathrm{X}$ & 58,33 & 7 \\
\hline Práticas Corporais & & & & & & X & & & & & & & 8,33 & 1 \\
\hline Direito Social & & & & & $\mathrm{X}$ & & & & $\mathrm{X}$ & $\mathrm{X}$ & & & 25,00 & 3 \\
\hline Tempo Livre & & & & & & & & & & & $\mathrm{X}$ & & 8,33 & 1 \\
\hline
\end{tabular}

\section{$1^{a}$ Pergunta: $O$ que é lazer para você?}

Ao se analisar as Unidades de Significados presentes no Quadro 1, é possível identificar o elevado grau de convergência na unidade que entende o lazer a partir de uma VISÃO FUNCIONALISTA, totalizando 58,33\% dos entrevistados que compreendem o lazer a partir dessa perspectiva.

Marcellino (1987, p. 38) conceitua a visão funcionalista do lazer, definindo-a como:

[...] altamente conservadora, que busca a "paz social", a manutenção da "ordem", instrumentalizando o lazer como fator que ajuda a suportar a disciplina e as imposições obrigatórias da vida social, pela ocupação do tempo livre em atividades equilibradas, socialmente aceitas e moralmente corretas.

É importante ressaltar também, que a compreensão funcionalista do lazer busca, sobretudo, a manutenção do "status quo" (MARCELLINO, 1987), procurando mascarar a sua verdadeira intenção, por meio de um falso humanismo, de legitimar a ordem social vigente. 
Isayama (2002) afirma que este entendimento encontra-se muito presente na prática pedagógica dos educadores do lazer, o que, de certo modo, acaba por contribuir para uma vivência mecanizada, concebendo o corpo dos alunos enquanto objeto das atividades propostas.

De acordo com Marcellino (1987), são quatro as principais abordagens funcionalistas do lazer - "romântica, moralista, compensatória e utilitarista". A primeira se caracteriza pela ênfase nos valores tradicionais e pela nostalgia ao passado; na abordagem "moralista", encontram-se discursos como "o lazer tem valiosas funções”, "lazeres convenientes desenvolvem", "lazeres perigosos podem desintegrar a vida". Nesta concepção, ratifica-se uma visão em que o lazer é entendido como algo "construtivo", o qual pode contribuir para a "ordem e a segurança social".

De acordo com Melo (2003), a ênfase "moralista" considera que o lazer possui o "poder" de moralizar as pessoas, "afastando as crianças das ruas e as pessoas dos vícios" sem levar em consideração outras variáveis que podem implicar nesse processo, como condições dignas de moradia, de saúde, de emprego e de educação.

Por sua vez, as abordagens "compensatória e utilitarista" apresentam relação com o trabalho alienado, mecânico, fragmentado e especializado da sociedade moderna. Nesta ótica, a visão "compensatória" do lazer tem a função de "compensar" a insatisfação e a alienação provocada pelo trabalho, utilizando o lazer como "fuga" dos problemas da vida cotidiana.

A perspectiva "utilitarista" se caracteriza por reduzir a compreensão do lazer à recuperação da força produtiva para o trabalho, o que significa entendê-lo apenas como um ato de descansar. Assim, as vivências de lazer têm o mero intuito de deixar o trabalhador "pronto" para mais um dia de labor (MARCELLINO, 1987). 
A partir do esclarecimento desses autores, é possível constatar que as concepções funcionalistas do lazer estão articuladas, de maneira específica/explicita, para manter a ordem social desigual vigente por parte dos detentores do poder, sem que essa ordem sofra questionamentos e sem que se possa levar ao conflito e a busca de novos valores.

Foi possível identificar este entendimento "funcionalista" em vários trechos dos relatos dos alunos entrevistados, com destaque para a fala do sujeito 1: "lazer é uma atividade não-obrigatória que nos faz relaxar das atividades obrigatórias diárias". Destaca-se também a afirmação do sujeito 4, ao dizer que lazer "é algo que você faça sem obrigação nenhuma, que tu faça com prazer e sem pressão" e os relatos dos sujeitos 3, 7 e 12, ao afirmarem, respectivamente, que lazer é "um momento em que eu vou descansar, isso pra mim é o lazer" e "é um estado de sair da rotina [...] é algo que não seja um compromisso formalizado".

É afirmada a posição de que não significa negar a importância da dimensão do descanso e do prazer nas atividades de lazer, mas, ao considerar apenas este viés, o educador estará tendo uma visão reduzida do lazer, não levando em consideração a importância do desenvolvimento social e educacional que essas vivências podem proporcionar as pessoas (MARCELLINO, 1987; ISAYAMA, 2010).

Por meio dos relatos dos discentes, é possível identificar que o entendimento da maioria dos alunos gira em torno do lazer enquanto algo "para relaxar", "sair da rotina", como um "espaço para descansar", ou como o sujeito 2 afirma: "um momento onde o indivíduo encontra-se livre das suas obrigações cotidianas e visa descansar, sair da rotina mesmo". 
Por outro lado, foi possível constatar a Unidade de Significado "DIREITO SOCIAL", a qual obteve a segunda maior convergência entre os alunos. Nesta Unidade, 3 discentes sustentaram um entendimento do lazer enquanto direito social, diferenciando-se, portanto, da maioria dos outros partícipes do estudo.

Neste cenário, destaca-se a afirmação do sujeito 9, ao expor que entende o lazer como sendo "um direito social, assim como qualquer outro direito de saúde, de educação, o lazer também é um direito social, ele é importante” . O sujeito 10 afirma que "realmente, entendo o lazer como uma questão de direito social, assim como é a saúde, assim como é a educação, a alimentação, o lazer é um direito do qualquer cidadão".

Sob esse prisma, pode-se identificar que, na atualidade, o lazer está presente em diversas leis ${ }^{7}$ que o garantem como direito social, como política pública e o tratam como dever do Estado em proporcionar espaços e vivências nesse âmbito de nossas vidas.

De acordo com os estudos de Marcellino (2008), constata-se a inserção do lazer na própria Constituição brasileira de 1988, por meio do Título II, Capítulo II e artigo $6^{\mathrm{a}}$, em que aparecem como direitos sociais "a educação, a saúde, a alimentação, o trabalho, a moradia, o lazer, a segurança, a previdência social, a proteção à maternidade e à infância, a assistência aos desamparados, na forma desta Constituição" (BRASIL, 1988).

O lazer também pode ser visto no Título VIII - Da Ordem Social- Capítulo III Da Educação, da Cultura e do Desporto- seção III - Do Desporte - Art. 217, item IV e $§$

\footnotetext{
${ }^{7}$ Montenegro $(2012 ; 2014)$ ressalta que o lazer é abordado também na Política Nacional para a integração das Pessoas com Deficiência - Decreto lei n ${ }^{\circ} 3.298$, Legislação do Sistema Único de Saúde - SUS, lei ${ }^{\circ}$ 8.080 , na lei $n^{\circ} 10.216$, que dispõe sobre a proteção e os direitos das pessoas portadoras de transtornos mentais
} 
$3^{\circ}$, o qual expressa que "O Poder Público incentivará o lazer, como forma de promoção social” (BRASIL, 1988).

Outro destaque, na fala dos alunos, diz respeito à preocupação que o sujeito 9 demonstrou ter em relação a forma funcionalista que o lazer é tratado em muitas ações de políticas públicas e privadas. Ele afirma que "o lazer não deve ser visto como uma forma de amenizar os problemas sociais, mas sim, como um direito de todo mundo ter acesso digno a ele, direito pleno a ele".

Neste caminho de discussões, situam-se os estudos de Mascarenhas (2004, 2007) quando ressalta que o lazer, entendido como direto social e alçado ao conjunto das políticas públicas, tem sido parte integrante da indústria capitalista e da proliferação de políticas assistencialistas.

Este contexto nos revela a existência do que o autor denomina de sem-lazer:

Os sem lazer podem ser visto aqui como aqueles setores da população que se encontram à margem do mercado de consumo e equipamentos de lazer, não tendo, também, essa necessidade devidamente atendida pelas políticas de governo. São, por exemplo, conforme dados levantados pela fundação Perseu Abramo (1999), milhares de jovens que nunca tiveram a oportunidade de ir ao cinema (15\%), ao teatro (46\%), a um show (29\%), ao museu (52\%) a biblioteca $(40 \%)$ (MASCARENHAS, 2007, p. 26.).

Estas discussões assumem uma relevância central para compreensão da sociedade como um todo, pois, assim como o lazer não deve ser visto de forma isolada de um contexto social mais amplo, advoga-se que o mesmo pode proporcionar vivências compromissadas com a formação de uma sociedade mais justa.

Ressalta-se, portanto, o pequeno número de alunos entrevistados que demonstrou ter este entendimento do lazer, compreensão que precisa ser compartilhada pelos futuros professores ao se ter em vista buscar uma atuação mais criativa e crítica nos espaços de vivências destinados ao lazer. 
A segunda questão geradora a ter as suas Unidades de Significados desveladas surgiu com base na intenção de compreender se os alunos atribuem importância à discussão do lazer em sua formação e identificar se a disciplina ligada a temática do lazer, cursada na graduação, atendeu aos seus anseios profissionais, ficando assim redigida: A DISCIPLINA SOBRE LAZER QUE VOCÊ CURSOU DURANTE A SUA FORMAÇÃO ATENDEU AS SUAS EXPECTATIVAS PROFISSIONAIS? JUSTIFIQUE.

Nessa questão, foram identificadas, inicialmente, doze unidades de significados. Como na primeira pergunta, as entrevistas foram relidas várias vezes, agrupou-se as unidades que mais se equiparavam e chegou-se ao total de quatro Unidades de Significados mais representativas dos pensamentos dos alunos, assim demonstradas no Quadro abaixo.

\section{Quadro 2: Unidades de significados da segunda questão}

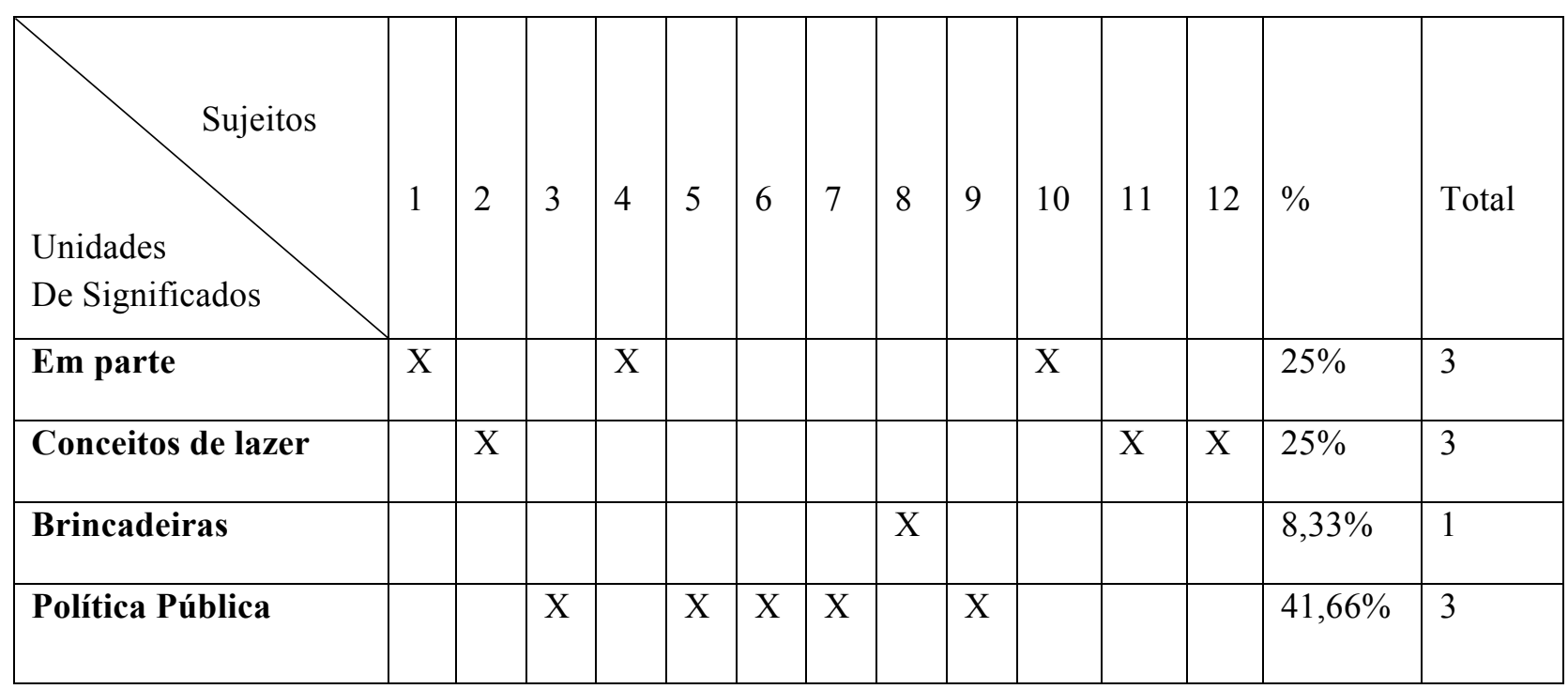

$2^{\text {a }}$ Pergunta: A disciplina sobre lazer que você cursou durante a sua formação atendeu as suas expectativas profissionais? Justifique.

Ao consultar o quadro em questão, o leitor poderá perceber que a maior convergência entre os relatos dos alunos ocorreu na Unidade de Significado Política 
Pública. Assim, 41,66\% dos entrevistados afirmaram que a disciplina sobre lazer atendeu as suas expectativas em virtude de ter possibilitado um debate sobre o lazer com o enfoque nas políticas públicas.

Essa afirmação pode ser demonstrada por meio do discurso do sujeito 9, ao revelar que a disciplina o auxiliou a "[...]conceituar o que é lazer e compreender esse fenômeno do lazer além do senso comum, e compreender o lazer de forma crítica, acho que, não só na mera reprodução, não só no papel de animador cultural, mas também ver o lazer como um direito social e político".

O sujeito 6 também destacou o fato da disciplina ter colaborado para que ele pudesse ter este entendimento do lazer, afirmando que a "[...]disciplina ela foi mais além do que a minha expectativa [...] devido pensar na questão do lazer e a cidade, lazer e a cidadania, lazer e a política"

O discente afirmou que a partir da sua vivência na disciplina, passou a perceber que os espaços de lazer estão sendo cada vez mais apropriados na lógica do consumo, afirmando:

\begin{abstract}
"Se você analisar, você fala tanto do lazer, mas cadê os espaços apropriados para o lazer? Cada vez mais o privado toma conta, pra fazer lazer em academia ou em alguma coisa desse sentido você paga. Então não tem mais esse tempo que você jogava uma bola, hoje não, se você quiser, você tem que pagar. Por isso que eu te digo que a disciplina ela foi além da minha expectativa, ela despertou uma consciência do lazer, da importância do espaço que vai ser apropriado como equipamento do lazer, coisa que as vezes passa despercebido, as mudanças vão acontecendo tão rápido que você não para pra refletir como está o espaço de lazer, e os espaços que tem realmente apropriado para o lazer são os privados realmente e não público. Então, nesse caso, a disciplina despertou essa consciência crítica do lazer".
\end{abstract}

As ponderações empreendidas pelo discente refletem, como ponto de vista, a realidade do lazer enquanto política pública: cada vez mais esse fenômeno social, que é 
um direito garantido na constituição, destina-se a lógica do consumo desenfreado, da desapropriação dos já poucos espaços públicos existentes e da distância de um efetivo acesso ao lazer destinado às camadas populares.

Outro aspecto a chamar atenção decorre da Unidade de Significado EM PARTE, a qual obteve convergência de $25 \%$ dos alunos que afirmaram que a disciplina atendeu em parte as suas expectativas profissionais.

O sujeito 10 afirmou:

“[...] enquanto disciplina, eu penso que como todas as disciplinas, elas são bem rasteiras, são bem superficiais [...] enquanto disciplina mesmo, como todos as outras eu vejo de uma forma bem superficial [...] com todas as debilidades de uma disciplina que acontece em três, cinco ou quatro meses".

Neste caminho de raciocínio, autores como Marcellino (2010), Montenegro (2012, 2014), Isayama (2002, 2010), Gomes (2010) indicam a fragilidade de se abordar uma temática como o lazer em apenas uma disciplina. Em suas análises, os pesquisadores evidenciam que essa forma de discutir o tema nos cursos de formação acaba por proporcionar espaços reduzidos de debate, pouca possibilidade de instrumentalização dos conhecimentos apreendidos e, por conseguinte, em uma formação superficial e pouco aprofundada.

Merece destaque também as falas dos sujeitos 1 e 4 . Os discentes afirmaram que a disciplina "[...] contribuiu em parte, ficando em, "rodeios" na questão do lazer como direito social, e eu acho que a gente viu pouco de outros temas do lazer, pouco do campo de atuação do lazer" (SUJEITO 1).

O sujeito 4 ressaltou que:

“[...] não foi totalmente que atendeu as minhas expectativas, mas foi até um pouco além, foi mais das políticas públicas na verdade o lazer, a discussão sobre o que o governo faz, perante ao lazer no estado do 
Pará na verdade, mas em relação ao lazer propriamente dito foi discutido pouco, por isso que eu falo em parte".

Para melhor dialogar com o relato dos alunos recorre-se às ponderações de Nóvoa (1992, 2007, 2008). O educador mostra a necessidade de, nos cursos de formação de professores, aproximarmos os formandos com o campo de atuação, de facilitar o contado com as práticas do cotidiano profissional e da partilha de saberes com os professores mais experientes.

Essa questão também é abordada por Imbernón (2010), ao revelar que a formação docente ganharia em qualidade se girasse em torno de experiências advindas de situações concretas da realidade em que o profissional atua.

Percebe-se que os alunos expuseram essa fragilidade no que concerne a formação no âmbito do lazer, pois ambos afirmaram a necessidade de haver mais espaços formativos que pudessem aproximar a disciplina com o campo de atuação do profissional em lazer, o que poderia criar maiores oportunidades de reflexão sobre a própria prática pedagógica desenvolvida nos espaços de atuação, como clubes, acampamentos, colônia de férias, spas, cruzeiros e políticas públicas e privadas de esporte e lazer. A realização de ações formativas, as quais possam aproximar o discente com o seu campo de atuação, podem auxiliar na instrumentalização do conhecimento construído nos espaços de sala de aula das universidades.

\section{Considerações Finais}

A compreensão do lazer na atualidade perpassa pelo entendimento do mesmo como direito social e vivência no plano da cultura caracterizada pela ludicidade das manifestações. Neste sentido, quando se fala em formação para atuação em lazer, 
advoga-se compreendê-la como um processo que está desafiado a refletir sobre a sociedade e o lugar que o lazer tem para proporcionar uma vida com mais qualidade as pessoas.

No caminhar dessa pesquisa, partiu-se da crítica a ênfase "didáticometodológica" que historicamente assumiu a discussão do lazer como conhecimento trabalhado na formação do professor de Educação Física. Nessa direção, deparou-se com diversos autores, que em suas produções acadêmicas, revelaram constantes fragilidades nos processos formativos de profissionais para atuação nos espaços de lazer.

Quanto ao relato dos discentes, identificou-se que 58,33\% dos partícipes do estudo demonstram ter um entendimento "funcionalista" do lazer, entendendo-o, sobretudo, como "algo para descansar", "para sair da rotina" e para "relaxar" das obrigações diárias. Embora esta tenha sido a compreensão mais recorrente nas falas dos alunos, foi possível perceber outras formas de entender o lazer, tais como direito social e tempo livre.

Em relação à segunda questão geradora do estudo, constatou-se que 41,66\% dos entrevistados afirmaram que a disciplina sobre lazer atendeu as suas expectativas profissionais por trabalhar conteúdos sobre política pública. Por outro lado, 25\% afirmou que a disciplina atendeu apenas em parte, em virtude de um pequeno espaço destinado as discussões de lazer nos currículos dos cursos.

Desta forma, espera-se que os resultados aqui apresentados possam contribuir para a melhoria do processo de formação desenvolvido nas instituições pesquisadas, em especial no que concerne a interface Educação Física/Lazer. 
É importante destacar que o espaço destinado à discussão do lazer nas instituições é pequeno, fato esse que se coloca como um limite para a formação. Nesse sentido, coloca-se como sugestão para as instituições a necessidade de se ampliar as oportunidades de debate dessa temática no currículo dos cursos, o que pode ser alcançado por meio da inclusão de disciplinas com discussões que envolvam políticas públicas de lazer, experiências de extensão e elaboração de projetos nesse campo de conhecimento e desenvolvimento de pesquisa e formação continuada na área do lazer.

\section{REFERÊNCIAS}

ANDRÉ, Marli; LÜDKE, Menga. Pesquisa em educação: abordagens qualitativas. São Paulo: EPU, 1986.

CAMPOS, Emerson Araújo de; ALENCAR, Joelma Monteiro. Lazer e Educação Física: encontros e desencontros entre formação e transformação. In: ARAÚJO, Patrícia de (Org.) Lazer, Formação e Meio Ambiente: Subsídios para as políticas públicas em Belém do Pará. Rio de Janeiro: Lecsu, 2013. p. 251-267.

BRASIL. Constituição da República Federativa do Brasil de 1988. Brasília, 5 out. $1988 . \quad$ Disponível em: $<$ http://www.planalto.gov.br/ccivil_03/constituicao/constitui\%C3\%A7ao.htm>. Acesso em: 25. jan. 2010.

CHIZZOTTI, A. Pesquisa em ciências humanas e sociais. São Paulo: Cortez, 2005.

DUARTE, Rosália. Pesquisa qualitativa: reflexões sobre o trabalho de campo. Cadernos de Pesquisa, São Paulo, n. 115, p. 139-154, 2002.

GOMES, Cristiane Luce. Significados de recreação e lazer no Brasil: reflexões a partir da análise de experiências institucionais (1926-1964). 2003. 322f. Tese (Doutorado em Educação)- Faculdade de Educação, Universidade Federal de Minas Gerais, Belo Horizonte, 2003.

Lazer, Trabalho e Educação: relações Históricas, questões contemporâneas. Belo Horizonte: Ed. UFMG: CELAR-DEF/UFMG, 2010.

IMBERNÓN, Francisco. Formação docente e profissional: formar-se para a mudança e a incerteza. São Paulo: Cortez, 2010.

ISAYAMA, Helder Ferreira. Recreação e Lazer como integrantes de currículos dos cursos de graduação em Educação Física. 2002. 205f. Tese (Doutorado em Educação 
Física)- Faculdade de Educação Física, Universidade Estadual de Campinas, Campinas, 2002.

. Recreação e lazer na formação profissional em Educação Física: reflexões sobre o currículo. In: WERNECK, C. L.; ISAYAMA, H. F. (Org.). Lazer, recreação e educação física. Belo Horizonte: Autêntica, 2003. p. 173-214.

ISAYAMA, Helder Ferreira. Atuação do Profissional de Educação Física no âmbito do Lazer: a Perspectiva da Animação Cultural. Motriz, Rio Claro, v.15, n.2, p.407-413, abr./jun. 2009. Disponível em: http://clubedosrecreadores.com/clubeintelectual/22.pdf, Acesso em: 22 Nov. 2014.

Formação Profissional no âmbito do lazer: desafios e perspectivas. In: ISAYAMA, Helder (Org.). Lazer em Estudo: currículo e formação profissional. Campinas: Papirus, 2010. p. 9-25

MARCELLINO, Nelson Carvalho. Lazer e Educação. Campinas: Papirus, 1987.

Subsídios para uma política pública de lazer: o papel da administração municipal. In: MARCELLINO, Nelson Carvalho (Org.). Políticas públicas de lazer. Campinas: Editora Alínes, 2008. p. 11-16.

A relação teoria e prática na formação profissional em lazer. In: ISAYAMA, Helder (Org.). Lazer em Estudo: currículo e formação profissional. Campinas: Papirus, 2010. p. 59-85.

MASCARENHAS, Fernando. O lazer como prática da liberdade: uma proposta educativa para a juventude. Goiânia: Ed. UFG, 2004.

Outro lazer é possível! Desafio para o esporte e lazer da cidade. In: Lino Castellani Filho. (Org.). Gestão pública e política de lazer: formação de agentes sociais. 1ed.Campinas: Autores Associados, 2007, v. , p. 17-40.

MELO, Victor Andrade de. Lazer e educação Física: Problemas historicamente construídos, saídas possíveis - um enfoque na formação. In: WERNECK, C. L.; ISAYAMA, H. F. (Org.). Lazer, recreação e educação física. Belo Horizonte: Autêntica, 2003.p. 57- 76.

MONTENEGRO, Gustavo Maneschy . Conhecimento sobre o lazer na formação de professores de Educação Física: um olhar sobre os cursos superiores das universidades públicas em Belém/PA. 2012. 190f. Dissertação (Mestrado em Educação) - Instituto de Ciências da Educação, Universidade Federal do Pará, Belém, 2012.

Conhecimento sobre o lazer nos cursos de Educação Física de Belém-PA. Jundiaí: Paco Editorial, 2014. 133p.

MOREIRA, Wagner Wey; SIMÕES, Regina; PORTO, Eliene. Análise de Conteúdo: técnica de elaboração e análises de unidades de significado. Revista Brasileira de Ciência e Movimento. Brasília, v. 13, n. 4, p. 107-114, out. 2005. 
NÓVOA, Antônio. Formação de Professores e Profissão Docente. In: NÓVOA, Antônio (Org.). Os Professores e sua formação. Lisboa: Dom Quixote, 1992. p.15-33.

O regresso dos Professores, 2007. Disponível em: $<$ http://escoladosargacal.files.wordpress.com/2009/05/regressodosprofessoresantoniono voa.pdf.> Acesso em: 02 Fev. 2010.

NÓVOA, Antônio. Para uma formação de professores construída dentro da profissão, 2008.

Disponívelem: $<$ http://www.revistaeducacion.mec.es/re350/re350_09por.pdf. $>$ Acesso em: 02 de Fevereiro de 2010.

PINTO, L. M. de M. Políticas Publicas de Lazer no Brasil: uma história a contar. In: MARCEllino, N. C. (Org.). Políticas públicas de lazer. Campinas: Editora Alínes, 2008. P. 79-95.

\section{Endereço do Autor:}

Gustavo Maneschy Montenegro

Rua José Maria Rosemburg 11, casa 4

Belo Horizonte - MG - 31340-080

Endereço Eletrônico: gustavo_maneschy@hotmail.com 